\title{
GESTÃO DO CONHECIMENTO EM PROJETO DE EaD: O CASO PAI/UFSC
}

\author{
Aline Pereira Soares (EGC/UFSC - alinepsoares@yahoo.com.br) \\ Marina Keiko Nakayama (EGC/UFSC - marina@egc.ufsc.br) \\ Luis Roque Klering (EGC/UFSC e EA/UFRGS - lrklering@ea.ufrgs.br) \\ Ricardo Silveira Azambuja (INE/UFSC - silveira@inf.ufsc.br)
}

Resumo: O artigo apresenta um estudo de caso sobre o modo como ocorreu a gestão do conhecimento na parte coordenada pela Universidade Federal de Santa Catarina (UFSC), abrangendo alunos dos estados do Paraná, Santa Catarina, Rio Grande do Sul e Mato Grosso do Sul, do Projeto Aluno Integrado (PAI), promovido pelo Ministério da Educação e Cultura (MEC), no período de 2010 e 2011, na modalidade de EaD. Para analisar e compreender o caso, recorreu-se ao modelo das 5 fases do processo de criação de conhecimento proposto por Nonaka e Takeuchi (1997). A metodologia utilizada foi o estudo de caso do tipo exploratório e descritivo; levantamento de dados via documentos e entrevistas; e análise de dados com base na metodologia da Ground Theory (GT). Os resultados das análises apontaram a fase da socialização como etapa mais deficitária; e sugerem acrescentar a condição capacitora de conhecimento infraestrutura tecnológica, ao modelo proposto pelos autores.

Palavras-chave: Educação a Distância. Gestão do Conhecimento. Grounded-Theory. GT.

\section{KNOWLEDGE MANAGEMENT IN DISTANCE EDUCATION PROJECTS: THE PAI/UFSC CASE}

Abstract: This article presents a case study about how the knowledge management occurred in the part coordinated by the Federal University of Santa Maria (UFSC), which includes students from the states of Paraná, Santa Catarina, Rio Grande do Sul and Mato Grosso do Sul, who are part of the PAI - Projeto Aluno Integrado (Integrated Student Project), promoted by the Ministry of Education and Culture (MEC), in 2010 and 2011, in the Distance Education category. The model of five stages of knowledge creation proposed by Nonaka \& Takeuchi (1997) was used in order to analyze and comprehend the case. The methodology used was the exploratory and descriptive case study type; data collection through documents and interviews; as well as data analysis based on the Ground Theory (GT) methodology. The results of the analyses indicated the socialization phase as the most deficient stage, and suggested the addition of the technological infrastructure to the enabling knowledge condition model proposed by the authors.

Key-words: Distance education. Knowledge Management. Grounded Theory. GT.

\section{INTRODUÇÃO}

Atualmente, as organizações podem ser consideradas como organizações do conhecimento, quando adquirem a capacidade de usar a informação para criar significado, construir conhecimento e tomar decisões (SOARES, SOARES, 2007).

Na visão de Vygotsky (1987), a construção do conhecimento pelo sujeito se faz a partir de sua interação com o meio, sendo esta a base para o seu desenvolvimento. Desse modo, no processo de aprendizagem, faz-se necessário o envolvimento de agentes com expertises, que proporcionem o desenvolvimento dos alunos. Para tanto, o perfil deste profissional deve ser de um mediador, que esteja atento às demandas dos 
alunos, acompanhando-os, de forma a promover a interação via diálogo. Assim, o autor destaca que o conhecimento deixa de ser concebido como um produto (apenas conteúdo) e passa a ser trabalhado como consequência de um processo de interação para construção do sujeito, com base nas ações e no comportamento humano (VYGOTSKY, 1987).

A troca de informações via Tecnologias de Informação e Comunicação (TICs) torna-se um fator fundamental no processo de capacitação, uma vez que, para um país (e suas instituições) ser considerado intensivo em conhecimento é necessário, segundo Evers (2001), intensificar algumas variáveis, tais como: o número de patentes, número de pesquisadores, investimento em pesquisa e desenvolvimento, computadores por pessoa, acesso à internet, número de cientistas e engenheiros (P\&D), investimento/desenvolvimento de infraestrutura tecnológica, dentre outras. Essas variáveis separam e determinam se países têm ou não status de sociedade do conhecimento. Ou seja, o Brasil precisa investir cada vez mais em institutos de pesquisa e em universidades; em programas de inovação e nas áreas de P\&D das indústrias; na utilização das TICs; em investimentos que agreguem valor aos produtos e serviços.

Assim, a geração de conhecimento via educação é uma função primordial. Segundo tal perspectiva, o governo federal do Brasil, confirmando a importância da educação a distância para o desenvolvimento do país, tem investido na capacitação de professores e alunos. Exemplo de tal ação é o curso Projeto Aluno Integrado: Qualificação em Tecnologia Digital, para alunos do ensino médio, matriculados em qualquer escola da rede pública de ensino do Brasil, tendo sido ofertado pela primeira vez em 2010-2011, para 70 mil alunos, dos quais 15 mil estiveram sob a responsabilidade da UFSC. O curso é realizado a distância e conta com material, equipe e metodologia elaboradas exclusivamente visando a preparar melhor os alunos em relação às ferramentas da tecnologia digital. A primeira edição do curso gerou uma série de informações e relatórios na parte coordenada pela UFSC, que serviram como fonte de dados de pesquisa relatada nesse artigo, cujos achados visam subsidiar a realização de novas edições do curso, bem como o desenvolvimento da educação a distância em geral.

Na pesquisa, percebeu-se a necessidade de avaliar como aconteceu a gestão do conhecimento durante a realização da primeira edição do curso PAI, na parte coordenada pela UFSC. Com base no pressuposto da significativa relação entre educação a distância e gestão do conhecimento, definiu-se a seguinte questão de pesquisa: Como ocorreu a gestão do conhecimento na equipe de pessoas, oriundas de diferentes instituições e Estados do Brasil, que desenvolveu a parte do Projeto Aluno Integrado coordenado pela UFSC em 2010-2011?

Deste modo, neste artigo, o objetivo geral de estudo consiste em identificar como ocorreu a gestão do conhecimento na equipe de pessoas, oriundas de diferentes instituições e Estados do Brasil, que desenvolveu a parte da primeira edição do Projeto Aluno Integrado coordenado pela UFSC. E os objetivos específicos são: a) identificar quais foram as principais dificuldades para gerir o conhecimento; b) quais ações adotadas pela equipe coordenadora da UFSC contribuíram para a gestão do conhecimento; c) quais alterações podem melhorar a gestão do conhecimento.

\section{FUNDAMENTAÇÃO TEÓRICA}

\subsection{GESTÃO DO CONHECIMENTO}

As organizações podem ser consideradas atualmente como organizações do conhecimento. Para Choo (2003, p. 30), “a organização que for capaz de integrar 
diferentes processos de criação e significado, construção de conhecimento e tomadas de decisões pode ser considerada uma organização do conhecimento”. Portanto, os profissionais responsáveis pela gestão de pessoas devem estar preparados para atuarem no processo de gestão do conhecimento.

Nonaka e Takeuchi (1997) sugerem um modelo integrado de cinco fases do processo de criação (ou “espiral”) de conhecimento organizacional: 1) compartilhamento do conhecimento tácito; 2) criação de conceitos; 3) justificação de conceitos; 4) construção de um arquétipo e 5) difusão interativa do conhecimento (ver figura 1).

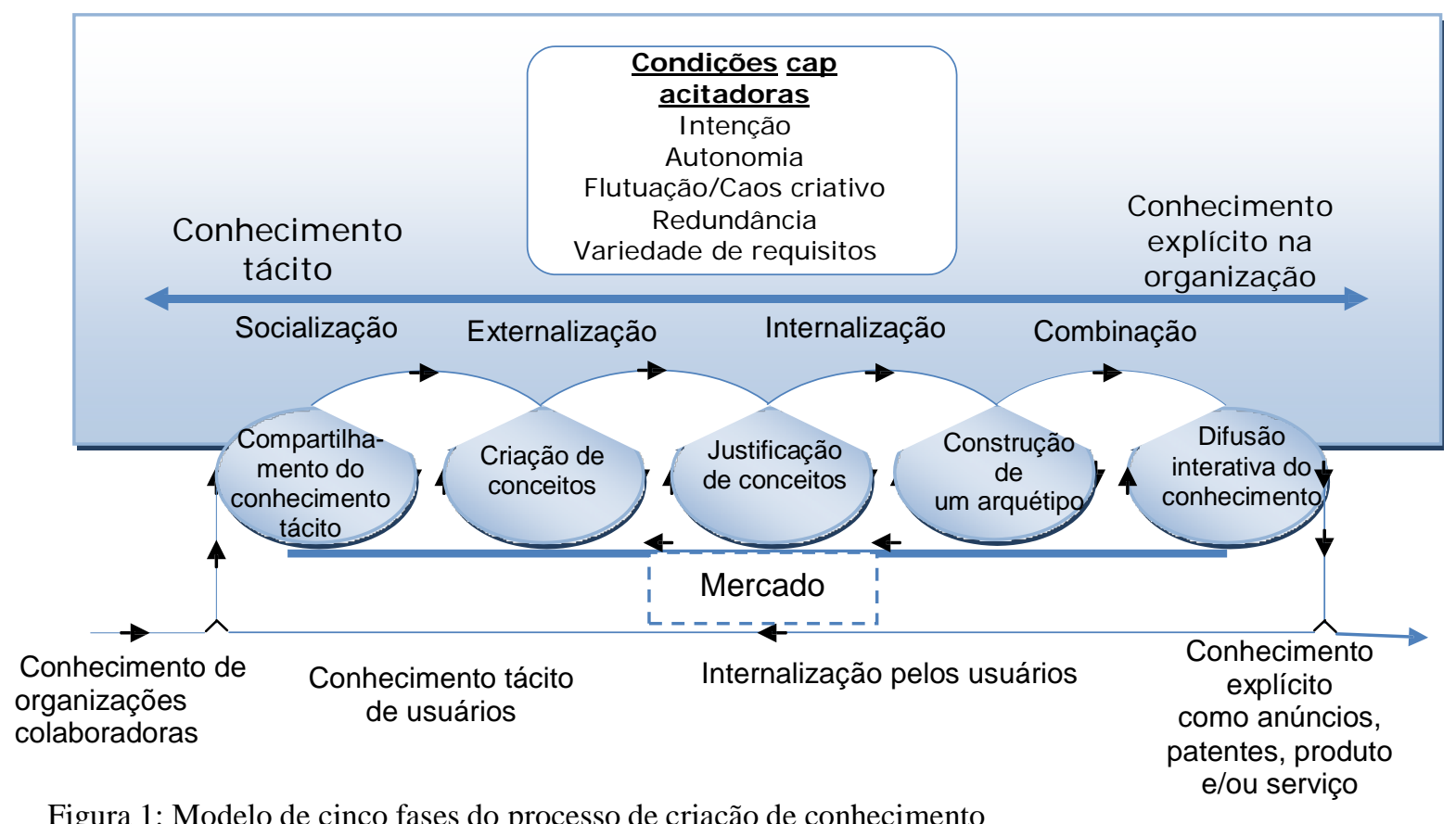

Figura 1: Modelo de cinco fases do processo de criação de conhecimento Fonte: Nonaka e Takeuchi (1997, p. 96)

Nonaka e Takeuchi (1997) referem que a criação de conhecimento organizacional é permeada por quatro modos de conversão do conhecimento, em diferentes níveis ou dimensões organizacionais (individual, grupal, setorial, divisional, organizacional e interorganizacional), gerando, pelas interações, a "espiral do conhecimento", dos níveis menores aos mais amplos:

a) Socialização: do conhecimento tácito em conhecimento tácito (compartilhado em nível organizacional mais amplo);

b) Externalização: do conhecimento tácito em conhecimento explícito;

c) Internalização: do conhecimento explícito em conhecimento tácito;

d) Combinação: do conhecimento explícito em conhecimento explícito (com conceitos melhor sistematizados).

Outrossim, relatam que a criação de conhecimento organizacional demanda condições (ou contexto) de capacitação (viabilização/ facilitação), que são:

a) Intenção: constitui a aspiração de uma organização em relação às suas metas; fornece o critério para avaliar um conhecimento;

b) Autonomia; amplia as possibilidades e estímulo para introduzir novos insights e conhecimentos na estrutura holográfica;

c) Flutuação e caos criativo: estimulam a interação interna com o ambiente externo, pela adoção de uma atitude aberta em relação aos sinais ambientais, podendo explorar a ambiguidade, a redundância ou os ruídos desses sinais para aprimorar seu próprio sistema de conhecimento; 
d) Redundância: refere-se à superposição intencional de informações, visando a compartilhá-las nos diferentes níveis ou dimensões organizacionais, permitindo assim que uns percebam e conheçam o que outros sabem;

e) Variedade de requisitos: de forma que a diversidade organizacional interna corresponda à variedade e complexidade do ambiente externo, viabilizando melhor ajuste e resposta aos desafios impostos.

Nonaka e Takeuchi (1997) destacam que, na primeira fase do modelo, o compartilhamento do conhecimento tácito é considerado um estilo de socialização e, como é importante e individual, precisa ser partilhado na empresa. O compartilhamento do conhecimento tácito é conexo ao processo de socialização, conforme supracitado; assim, é importante que as empresas disponibilizem um espaço de intercâmbio/ de troca de conhecimentos. Todavia, conforme os autores, deve haver cuidado nesse processo, pois nessa etapa os envolvidos podem apresentar perspectivas, histórias e objetivos diferentes.

A criação de conceitos é a etapa seguinte à socialização, em que acontece a externalização, uma vez que o modelo mental tácito é compartilhado recorrendo a palavras e diálogos e, por fim, sendo estruturado em conceitos explícitos. A variedade de requisitos auxilia o processo de conciliar diferentes perspectivas em uma única direção, para resolver diferenças de percepção. Este processo "é facilitado pelo uso de múltiplos métodos de raciocínio, tais como dedução, indução e abdução”, este último principalmente pelo emprego de metáforas e analogias (NONAKA; TAKEUCHI, 1997).

Em relação à etapa da justificação de conceitos (terceira etapa), os autores destacam que os novos conceitos precisam ser verdadeiramente justificados em algum momento do processo. É importante a organização justificar as novas informações e conceitos explicitamente logo após seu surgimento, porque é importante avaliar se este conhecimento atende aos anseios da sociedade.

A etapa da construção de um arquétipo (quarta etapa) acontece quando o conceito justificado é posteriormente transformado em algo tangível ou concreto. Arquétipo pode ser, por exemplo, um modelo ou protótipo de produto, e é construído pelo conhecimento explícito novo ao já existente, e por este motivo é semelhante à fase de combinação, em que ocorre a sistematização de conhecimentos explícitos (NONAKA; TAKEUCHI, 1997; NONAKA; TAKEUCHI; BYOSIERE, 2001). Como esta fase é complexa, faz-se necessária a participação de diferentes áreas (para ocorrer variedade de requisitos) cooperando para a criação do conhecimento organizacional e interoganizacional.

A última etapa (quinta) é a difusão interativa do conhecimento, que acontece quando a ocorrência que foi criada é justificada e transformada em modelo, passando por uma nova etapa de criação de conhecimento diferenciado. Essa fase de criação pode recomeçar e desenvolver novos processos, num ciclo virtuoso de aperfeiçoamento. Por isso, a criação de novos conhecimentos não é apenas a capacidade de aprender com os outros ou de adquirir conhecimentos externos, mas também de construir conhecimento novo, via interação com outros membros da organização (MORESI, 2001).

Assim, gestão do conhecimento não é uma simples questão de capturar, estocar e transferir informação, mas requer interpretação e organização da informação em múltiplas perspectivas (BHATT, 2001).

\subsection{EDUCAÇÃO A DISTÂNCIA}

No Brasil, a EaD apresenta-se como um importante instrumento de intercâmbio, articulação de conhecimento e informações, bem como de oportunidade de ensino e 
aprendizagem a milhões de pessoas; é mais importante ainda por constituir um território continental.

Segundo Moore, Kearsley (2012, p. 2), a principal característica da EaD é o aprendizado planejado que normalmente acontece em diferentes locais através do ensino. "Os resultados provêm de técnicas especiais no design do curso, técnicas instrucionais especiais, métodos especiais de comunicação através da eletrônica, bem como uma organização especial e arranjos administrativos”. Klering (2006) complementa esta perspectiva, apresentando algumas vantagens da $\mathrm{EaD}$, tais como: o grande número de alunos atendidos - ganho de escala; a disponibilização de materiais em formato digital - facilitando a organização e a busca/consulta; o desenvolvimento de materiais de ensino mais ricos e variados, tais como os de aprendizagem multimídia; e a possibilidade de apoio mais amplo à educação, por não se limitar a poucas horas diárias, nem a locais fixos, como no caso do ensino presencial.

Assim, o ensino na modalidade de EaD exige uma equipe multidisciplinar, com diferentes competências: docentes especializados nas áreas do curso, coordenadores, técnicos especializados, designer instrucionais, designers gráficos, monitores, revisores e tutores. E, de acordo com Simonson (2006), é importante que o ensino seja oferecido por instituições credenciadas, garantindo qualidade ao ensino; e aumentando a credibilidade do método.

Conforme dados do último Censo da Educação Superior do Ministério da Educação (INEP/MEC, 2008), há no Brasil uma permanente expansão do sistema de EaD. De 2003 a 2006, o número de cursos de graduação passou de 52 para 349, significando um aumento de $571 \%$. O crescimento no ingresso de estudantes nos cursos superiores na modalidade EaD também superou expectativas - passaram de 49 mil em 2003 para 207 mil em 2006, uma elevação de 315\%. O relatório também mostrou a existência, no Brasil, de 257 diferentes cursos credenciados, com mais de 970 mil alunos; evidenciando a grande expansão do ensino nesta modalidade.

\section{PROCEDIMENTOS METODOLÓGICOS}

Quanto ao tipo de estudo, caracteriza-se como exploratório, descritivo, documental, bibliográfico, teórico-empírico, estudo de caso. Em relação à abordagem, classifica-se como qualitativo.

Nesta pesquisa, foram coletadas informações dos integrantes da equipe do Projeto Aluno Integrado, coordenada pela UFSC, nos estados de Santa Catarina, Paraná, Mato Grosso do Sul e Rio Grande do Sul.

Os dados primários foram coletados junto a coordenadores de curso (que eram da UFSC), coordenadores de tutoria (também da UFSC), coordenadores de pólo (dos estados), supervisores, tutores a distância (da UFSC), tutores presenciais (em cada polo de ensino). Para a coleta de dados foram utilizadas entrevistas semiestruturadas, com perguntas que foram alteradas durante o trabalho de campo, conforme as análises das entrevistas iam sendo realizadas, tendo em vista o perfil dos entrevistados, como recomenda o método da GT. As perguntas estão apresentadas no Quadro 1 seguinte.

Quadro 1 - Perguntas das entrevistas

\begin{tabular}{|c|l|}
\hline QUESTÃO & \multicolumn{1}{c|}{ VARIÁVEL } \\
\hline 1 & Como funciona a gestão do curso de administração a distância? \\
\hline 2 & Como a equipe de EAD é preparada? \\
\hline 3 & Quais são as dificuldades enfrentadas pela equipe de EAD? \\
\hline 4 & O conhecimento adquirido pela equipe é passado ou armazenado de alguma forma? \\
\hline 5 & $\begin{array}{l}\text { Como acontece o compartilhamento do conhecimento “tácito” - conhecimento pré adquirido / } \\
\text { que cada pessoa possui, aquilo que não está escrito? }\end{array}$ \\
\hline
\end{tabular}




\begin{tabular}{|c|l|}
\hline 6 & $\begin{array}{l}\text { Caso aconteça, como o compartilhamento do conhecimento é formalizado/explicitado para } \\
\text { todos? }\end{array}$ \\
\hline 7 & $\begin{array}{l}\text { Como o curso promove/organiza a inserção e reforço para os membros da equipe dos novos } \\
\text { conceitos surgidos após as reuniões? Como transforma em algo tangível ou concreto? }\end{array}$ \\
\hline 8 & $\begin{array}{l}\text { Como acontece a difusão do conhecimento? Vocês possuem algum canal de comunicação para } \\
\text { aperfeiçoamento dos processos (por exemplo: ouvir a opinião deles)? }\end{array}$ \\
\hline 9 & E o conhecimento adquirido sobre esses casos é passado ou armazenado de alguma forma? \\
\hline
\end{tabular}

Fonte: Dados primários.

Foram entrevistadas 25 (vinte e cinco) pessoas, sendo: Coordenadores de curso (dois); Coordenadores do Proinfo, polos de PR, MS, SC (três); Equipe de acompanhamento e avaliação (dois); Supervisão (dois); Equipe Técnica (três); Orientadores de tutoria (seis) e Tutores de SC, MS, RS (três em cada polo). Os entrevistados estão identificados na pesquisa por números sequenciais, de 1 (um) a 25.

Para a análise dos dados foi utilizado o software ATLASti, que é específico para entrevistas qualitativas, tendo sido desenvolvido especialmente para auxiliar a construção de teorias, permitindo auditorias que verifiquem a validade e confiabilidade dos dados. As estratégias de análise adotadas foram: qualitativa, descritiva e interpretativa, análise do discurso; utilizando-se da metodologia da Ground Theory ou Teoria fundamentada, que auxilia na análise dos dados (STRAUSS; CORBIN, 2008).

\section{APRESENTAÇÃO DO PROJETO ALUNO INTEGRADO}

O Projeto Aluno Integrado (PAI) é parte do Programa Nacional de Formação Continuada em Tecnologia Educacional (Proinfo Integrado). O programa foi criado pela Portaria $n^{\circ}$ 522/MEC, de 9 de abril de 1997, com o nome de Programa Nacional de Informática na Educação (Proinfo). Em 2007, por meio do decreto 6300, passou a ser denominado Programa Nacional de Tecnologia Educacional (UFSC, 2010).

O Projeto Aluno Integrado tem como tema central: educação e tecnologia para um mundo melhor. Dentro desse tema, busca explorar diferentes perspectivas em todas as etapas da educação básica. O curso é oferecido para alunos a partir do nono ano do ensino fundamental, com carga horária de 180 horas (cinco meses), dividido em quatro módulos. Por meio de uma plataforma desenvolvida especialmente para o aprendizado de informática à distância, os jovens aprendem sobre educação a distância, história da informática, hardware (equipamentos), manutenção de computadores e sistemas operacionais.

\section{DESCRIÇÃO DOS RESULTADOS}

Com base nas análises das entrevistas foi possível identificar a categoria Gestão do Conhecimento e suas subcategorias: compartilhamento/socialização, construção de arquétipo, criação de conceitos, difusão e transmissão de conhecimento. Conforme a teoria, as subcategorias devem ser capazes de responder por variações consideráveis dentro da categoria selecionada para análise. Nesse artigo, a categoria Gestão do Conhecimento consegue explicar as variações (subcategorias) e também o ponto principal dos dados - ela é o fio condutor. O Quadro 2 a seguir apresenta a categoria Gestão do Conhecimento e suas subcategorias, que surgiram a partir das entrevistas.

Quadro 2 - resultados da análise da pesquisa - categoria gestão do conhecimento

\begin{tabular}{|c|c|c|}
\hline CATEGORIA & SUBCATEGORIAS & VARIÁVEIS E PERCEPÇÕES DOS RESPONDENTES \\
\hline \multirow{5}{*}{ Gestão do Conhecimento } & \multirow{5}{*}{$\begin{array}{l}\text { Compartilhamento do } \\
\text { Conhecimento/Socialização }\end{array}$} & Conhecimento tácito - muito a pouco aproveitado \\
\hline & & Reunião com o MEC - poucas \\
\hline & & $\begin{array}{l}\begin{array}{l}\text { Encontros presenciais } \\
\text { nenhum/suficiente }\end{array}\end{array}$ \\
\hline & & Interação entre os alunos - pouca \\
\hline & & Relatórios - poucos/Nenhum \\
\hline
\end{tabular}




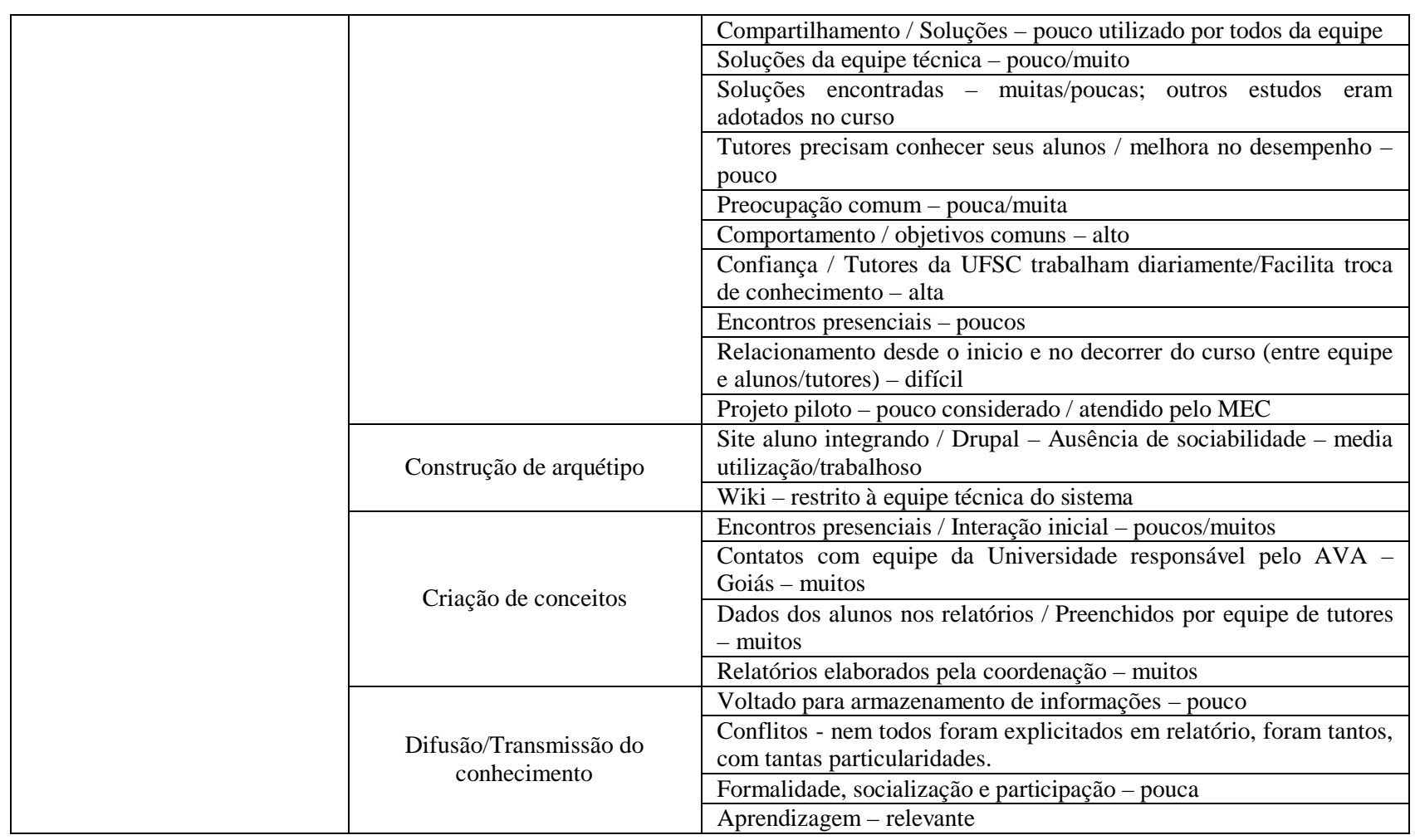

Fonte: Dados primários.

O primeiro momento do modelo de cinco fases de Nonaka e Takeuchi (1997) é compartilhamento do conhecimento - considerado um modo de socializar, que, por ser valioso e individual, necessita ser compartilhado na organização.

Segundo os entrevistados, além da capacitação inicial, aconteceu o Projeto Piloto em 2009, uma oportunidade para o MEC e os estados identificarem, via testes dos professores e secretarias dos estados e municípios (Seduc e Undime), as principais adaptações que o Programa Aluno Integrado precisaria implementar, antes de ser implantado. Todavia, apesar de elaborarem um relatório, muito pouco foi considerado (pelo MEC), conforme trechos de relatos a seguir:

No final de 2009, quando fizemos o piloto... foram levantadas várias fragilidades no sistema, e somente $20 \%$ foi contemplada. E não inseriram isso, essa solicitação dos tutores (ENTREVISTADO 1).

Nós fizemos uma avaliação com os tutores e nós colocamos algumas sugestões. Boa parte delas não foi utilizada (ENTREVISTADO 2)

Por outro lado, em relação à subcategoria socialização, ela aconteceu principalmente via recursos tecnológicos da equipe. Foram identificados os códigos: Sistema Aluno Integrado / Drupal, Voip e Gtalk como facilitadores da socialização; a preocupação comum, comprometimento/objetivos comuns; confiança; tutores da UFSC trabalham diariamente - como facilitadores das trocas de conhecimento. Mencionaram como deficiente o não atendimento às solicitações que eram feitas pela equipe de tutores e gestores (dos estados) no Projeto Piloto; a pouca quantidade de encontros presenciais; e a dificuldade no relacionamento desde o início e no decorrer do curso (entre equipe e alunos/tutores).

Outro desafio que percebo é fazer os tutores saberem que temos as mesmas preocupações que eles no sentido de evasão do curso, desmotivação dos alunos e inconstância do e-Proinfo e do Aluno Integrado, mas que temos limitações e não conseguimos resolver esses problemas - especialmente os de cunho técnico (ENTREVISTADO 3). 
Em relação à subcategoria construção de um arquétipo, essa acontece quando o conceito justificado é posteriormente transformado em algo tangível ou concreto, tal como um arquétipo ou protótipo de produto. Como esta fase é complexa, faz-se necessária a participação de diferentes áreas (variedade de requisitos) cooperando para a criação do conhecimento organizacional.

Caso as solicitações do Projeto Piloto original tivessem sido atendidas (ou boa parte delas fosse), poder-se-ia considerar, nesse estudo, o mesmo como sendo um protótipo. Todavia, depois de terminados os módulos do Projeto Aluno Integrado (com gestão da UFSC), vários entrevistados consideraram esse como sendo o protótipo.

Como a equipe da UFSC precisou de um arquétipo/ um protótipo, eles prepararam um arquivo de instruções, que ficou disponibilizado dentro do Sistema Aluno Integrado/ Drupal. De acordo com os dois entrevistados responsáveis pela equipe técnica da UFSC, tal material auxiliou a solucionar problemas, como os de vídeos, nas situações em que os computadores dos estados não tinham o software Flash instalado.

A outra subcategoria identificada foi criação de conceitos. Esta etapa do modelo de Nonaka e Takeuchi (1997) é posterior à de socialização, em que acontece a externalização, uma vez que o modelo mental tácito é compartilhado utilizando-se diálogos e palavras, e, por fim, estruturado em conceitos explícitos. Analisando as entrevistas observou-se que os diálogos aconteceram, mas foram principalmente para resolver problemas - utilizando-se de meios como o Voip, e-mail, site do Projeto Aluno Integrado/Drupal e reuniões presenciais.

A ocorrência da subcategoria Encontros presenciais pode ser considerada importante em todas as cinco (5) etapas do Modelo de criação de conhecimento de Nonaka e Takeuchi (1997); uma vez que os encontros apoiam ações em todas as fases do modelo.

Reforça-se a pouca quantidade de encontros ocorridos para promover o diálogo da equipe, principalmente diálogos com toda a equipe e que poderiam ter acontecido desde o início do projeto.

Até o final do curso, foi muito difícil o MEC reunir as três esferas da equipe: estado, MEC e universidades. Só tivemos uma reunião com os três grupos e foi na reunião que definimos o critério de aprovação, foi uma das poucas coisas que definimos em conjunto, em consenso. Levamos uma proposta, e os estados levaram outra, discutimos e adequamos, de modo bem tranqüilo, junto com o MEC. Isso foi um exemplo de como as coisas poderiam ter acontecido desde o início (ENTREVISTADO 6).

Segundo Nonaka e Takeuchi (1997), a difusão interativa do conhecimento acontece quando o acontecimento recém criado, justificado e transformado em modelo, passa por um novo ciclo de criação de conhecimento diferente, tanto dentro da organização quanto entre organizações. Tal fase de criação pode ser reiniciada, por exemplo, ouvindo a opinião dos usuários (feedback), que podem desencadear novos processos de melhorias e aperfeiçoamento do processo.

A partir das entrevistas, percebeu-se que muitas das informações que geraram novos conhecimentos eram armazenadas em relatórios e que os registros eram realizados principalmente por e-mails trocados entre a equipe (estados e UFSC). E entre a equipe da UFSC, quando aconteciam reuniões. Segundo os entrevistados, os conhecimentos gerados eram transmitidos por e-mail, Voip e chats. Já com a equipe da UFSC, a difusão do conhecimento acontecia principalmente nos momentos presenciais das reuniões - realizadas sem frequência certa (sempre que precisavam) ou por conversas informais

A pouca quantidade de encontros presenciais e reuniões foi destacada por boa parte dos entrevistados. 


\begin{abstract}
É importante ressaltar que a convivência com os demais orientadores de tutoria, bem como com a equipe toda do projeto, proporciona um grande crescimento pessoal. Pelo menos é a percepção que tenho. Os problemas são compartilhados, as dificuldades enfrentadas são discutidas e comunicadas. Nas conversas (na maioria das vezes informais), pontos de opinião diferentes são colocados em contraste e nesse momento ocorre um crescimento (ENTREVISTADO 7).
\end{abstract}

As melhorias e a aprendizagem que resultaram de tal processo foram consideradas relevantes pelos entrevistados, principalmente da UFSC. A aprendizagem surgiu, segundo os entrevistados, a partir da oportunidade de trabalharem com uma equipe diferente (em termos culturais, de idade, de estados), multidisciplinar e com necessidades específicas. Diante de inúmeros problemas (já apresentados) os tutores vivenciaram grande amadurecimento profissional, por estarem expostos a tantas variáveis. Nos estados, a aprendizagem foi mais relativa à metodologia/ prática do ensino, do que a aspectos voltados à aprendizagem individual, como no caso da UFSC.

Percebo que o papel do tutor em um curso a distância está muito além de cuidar (tal como define o wikicionário para a palavra "tutor", como sendo administrar ou cuidar dos bens de alguém incapaz); no caso dos nossos alunos, digo que "mediar" ou gerenciar as informações seria o termo mais correto a se utilizar e o papel nosso estaria em ser este mediador pedagógico (ENTREVISTADO 8).

Por isso, criar novos conhecimentos não é apenas a capacidade de aprender com os outros ou adquirir conhecimentos externos, mas também de construir por si mesmo via interação com outros integrantes da organização, permitindo a tentativa e erro, englobando ideias pessoais e ideias da organização.

O aprendizado que se tem através desta convivência com pessoas diferentes, com vidas, culturas, conhecimentos diversos; é imensurável. São visões diferentes de mundo que se refletem na forma de trabalhar, de orientar os alunos, de tomar decisões etc (ENTREVISTADO 10).

\title{
CONCLUSÕES
}

Constatou-se que, no modelo de cinco fases, a socialização foi uma das etapas mais deficientes no caso analisado. Outrossim, sugere-se a inserção da infraestrutura tecnológica (abarcando não somente os computadores, internet, Voip e outros, mas todas as tecnologias de apoio à criação de conhecimento, como é o caso do Ambiente Virtual de Aprendizagem (AVA) utilizado como suporte para a aprendizagem no curso enfocado) como mais uma condição capacitadora no modelo de Nonaka e Takeuchi (1997). O estudo evidencia que um AVA mais adequado que o usado seria muito importante e útil para melhorar o desempenho e a satisfação dos alunos num curso como o PAI; que gere os relatórios necessários, permita melhor interação/socialização das equipes, seja de fácil adaptação às solicitações dos integrantes; e que, principalmente, seja de fácil entendimento pelos usuários.

Deste modo, considera-se pertinente a indicação de Terra (2005), sobre a importância dos artefatos tecnológicos adequados para a gestão do conhecimento, e fazse um acréscimo ao modelo das condições capacitoras de Nonaka e Takeuchi (2008), incluindo mais uma vertente, especificamente nesse caso de estudo (e quem sabe para outras equipes e contextos de $\mathrm{EaD}$ ): a infraestrutura tecnológica.

Ressalta-se também que, nas situações de EaD, a socialização deve acontecer inclusive (e especialmente) presencialmente. Uma vez que, para equipes que nunca se viram e que estão distantes fisicamente, elas precisam se conhecer e criar alguma relação, gerando confiança inicial. Segundo Nakayama, Pilla e Binotto (2006), quando há confiança, passa a ocorrer nas equipes uma sinergia entre sentimentos, interesses, opiniões, propósitos e valores que se equilibram, se encontram e se assemelham. 


\section{REFERÊNCIAS}

BHATT, G. D. Knowledge management in organizations: examining the interaction between technologies, techniques, and people. Journal of Knowledge Management, v. 5, n. 1, p. 68-75, 2001.

CHOO, C. W. A organização do conhecimento. São Paulo: SENAC, 2003.

EVERS, Hans-Dieter. Towards a Malaysian Knowledge Society. Third International Malaysian Studies Conference (Msc3), Bangi, 2001.

INEP/MEC. Educacenso. Anuário Brasileiro Estatístico de Educação Aberta e a Distância. 4. ed. São Paulo, 2008. Disponível em: $<$ http://www.abraead.com.br/default.asp>. Acesso em: 10 dez. 2011.

KLERING, L. R. Plataforma de apoio ao ensino NAVi: ambiente interativo de aprendizagem. 2006. Disponível em: <http://eavirtual.ea.ufrgs.br>. Acesso em: $10 \mathrm{dez}$. 2011.

MOORE, M. G; KEARSLEY, G. Distance education: a systems view. 3. ed. [S.l.]: Wadsworth Publishing Company, 2012.

MORESI, E. A. D. Gestão da informação e do conhecimento. In: TARAPANOFF, K. O. Inteligência organizacional e competitiva. Brasília: Editora Universidade de Brasília, 2001.

NAKAYAMA, M. K.; PILLA, B. S.; BINOTTO, E. @-RH conceitos e práticas de RH eletrônico. Porto Alegre: UPF, 2006.

NONAKA, I; TAKEUCHI, H (Org.). Criação de conhecimento na empresa: como as empresas japonesas geram a dinâmica da inovação. 2. ed. Rio de Janeiro: Campus, 1997.

NONAKA, I; TAKEUCHI, H.(Org.) Gestão do conhecimento. Porto Alegre: Bookman, 2008.

NONAKA, I.; TOYAMA, R.; BYOSIERE, P. A theory of organizational knowledge creation: understanding the dynamic process of creating knowledge. In: DIERKES, M. et al.. Handbook organizational learning and knowledge. Oxford: Oxford University Press, 2001. p. 491-517.

ROSINI, A. M. As novas tecnologias da informação e a educação a distância. São Paulo: Cengage Learning, 2007.

SEDUC/GO. Secretaria de Educação do Estado de Goiás. Abertas incrições para curso de qualificação em tecnologia digital na UFG. Disponível em: $<$ http://www.educacao.go.gov.br/imprensa/?Noticia=3332>. Acessado em: 08 maio 2012.

SIMONSON, M.. Concepciones sobre la educación abierta y a distancia.. In: BARBERÀ, E. (Coord.). Educación abierta y a distancia. Barcelona: UOC, 2006.

SOARES, A. P.; SOARES, M. P. Gestão do conhecimento e criatividade: desafios na comunicação organizacional. In: SIMPÓSIO DE GESTÃO E ESTRATÉGIA EM NEGÓCIOS, 5.,2007, Rio de Janeiro. Anais... Rio de Janeiro: UFRRJ, 2007. 1 CDROM

STRAUSS, A.; CORBIN, J. Pesquisa qualitativa: técnicas e procedimentos para o desenvolvimento de uma teoria fundamentada. 2. ed. Porto Alegre: Artmed, 2008.

TERRA, J. C. C. Gestão do Conhecimento: o grande desafio empresarial. 3. ed. São Paulo: Negócio, 2005.

UFSC. Universidade Federal de Santa Catarina. Projeto Aluno Integrado. Disponivel em: <http://www.alunointegrado.ufsc.br/node/2>. Acesso em: 19 out. 2010.

VYGOTSKY, L. Pensamento e linguagem. São Paulo: Martins Fontes, 1987. 